\title{
O gênero discursivo reportagem de revista: um estudo de suas características e análise de exemplares da revista Istoé
}

Thiago Santos da Silva ${ }^{1}$

\begin{abstract}
Resumo: Este trabalho tem o objetivo de identificar como se configura a reportagem de revista como gênero discursivo, a partir de estudos prévios, e verificar de que modo esses aspectos são instanciados em exemplares veiculados em uma revista de circulação nacional. Esse estudo visa a apontar alguns aspectos que podem ser considerados no trabalho em sala de aula de língua portuguesa (LP), uma vez que as principais normativas que norteiam a prática docente, como os PCNs, indicam o ensino de LP a partir da noção de gêneros textuais/discursivos.
\end{abstract}

Palavras-chave: Gênero discursivo. Reportagem de revista. Contexto. Texto.

\section{Introdução}

É inquestionável afirmar quão importante, para o ensino de língua, tanto materna quanto estrangeira, é o trabalho em sala de aula com gêneros discursivos. As principais normativas que norteiam a atividade docente de ensino básico, como os Parâmetros Curriculares Nacionais (PCNs) (BRASIL, 1998), recomendam a inclusão do estudo de gêneros nas aulas de língua portuguesa.

Concomitantemente impulsionadas e aliadas ao advento dessas orientações pedagógicas, muitas pesquisas e teorias, em contexto tanto internacional quanto brasileiro, dedicam-se a discutir o estudo dos gêneros discursivos. Autores como Bakhtin (1992), Bazerman (2005), Miller (1994), Swales (1990), Bronckart (1990), entre outros, são alguns dos pesquisadores que procuraram compreender o funcionamento dos gêneros na sociedade. Todos esses autores, embora apresentem perspectivas teóricas distintas, adotam uma abordagem social da linguagem, ou seja, compartilham a premissa de que toda análise textual, em seus aspectos temáticos, organização retórica e estruturas linguísticas, deve estar preocupada em estudar os objetivos comunicativos compartilhados pelos falantes em atividades sociais realizadas em contextos específicos.

\footnotetext{
${ }^{1}$ Mestre em Letras, área de concentração Estudos Linguísticos, pela Universidade Federal de Santa Maria (2012). Atualmente desenvolve a atividade de professor temporário do Departamento de Letras Clássicas, Filologia e Linguística na UFSM. Desde 2010, atua como professor-tutor do Curso de Letras-EAD da UFSM. É membro do Núcleo de Estudos em Língua Portuguesa (NELP/UFSM). Tem se dedicado a estudar a relação entre linguagem e sociedade, considerando especificamente questões de gênero social, sexualidade, gêneros discursivos e mídia. E-mail: thiago.letras@gmail.com.
} 
É no encalço dessa perspectiva que o presente artigo se desenvolve, pois, baseando-se na visão de que existe uma intrínseca relação entre linguagem e sociedade, objetivamos averiguar como um gênero jornalístico se configura considerando seus aspectos contextuais e suas características textuais, a fim de indicar alguns aspectos que podem ser considerados no trabalho com gêneros jornalísticos em sala de aula.

Para cumprirmos esse objetivo, o presente artigo está organizado da seguinte forma: a) apresentação dos pressupostos teóricos que orientam a pesquisa, b) descrição do percurso metodológico utilizado para a realização das análises, c) análise de exemplares do gênero selecionado para estudo, e) considerações finais.

\section{Pressupostos teóricos}

Nesta seção, cuja função é apresentar as teorias que embasam esta pesquisa, inicialmente são apresentadas noções acerca do conceito de gênero. Em seguida, disserta-se a respeito de como as áreas do Jornalismo e da Linguística têm pesquisado o gênero jornalístico reportagem, para, por fim, discorrer acerca da importância do contexto na análise de qualquer prática discursiva.

\subsection{Concepções de gênero}

O conceito de gênero é tratado desde a Antiguidade, com a Retórica de Aristóteles, mas, sem dúvida, só ganhou notoriedade a partir das reflexões propostas pelo filósofo da linguagem Mikhail Bakhtin (1992) nos consagrados textos O problema do texto e Os gêneros do discurso. É nesse segundo ensaio que Bakhtin apresenta sua definição para gêneros discursivos, "tipos relativamente estáveis de enunciados" (1992, p. 279). Esse conceito possibilitou uma nova visada a respeito dos estudos de gêneros, pois atribui a essas realizações linguísticas um caráter sócio-histórico, interacional e ideológico. Com essas reflexões, Bakhtin abre espaço para se estabelecerem outras perspectivas teóricas que entendem gênero discursivo como "ações sócio-discursivas [utilizadas] para agir sobre o mundo e dizer o mundo" (MARCUSCHI, 2002, p. 22). Dessa forma, essas abordagens preocupam-se em estudar os gêneros mais por suas funções discursivas do que por suas particularidades linguísticas e formais - isso não significa que essas últimas não sejam importantes, mas devem ser vistas como colaboradoras na realização do propósito comunicativo ao qual o gênero serve. 
Uma perspectiva que segue essa visão de ação social é a sociorretórica. Para essa abordagem, conforme Miller (2009, p. 22), gênero é concebido como ação retórica tipificada, isto é, a partir de um dado propósito comunicativo estabelecido, recorremos a situações anteriores que consideramos análogas (tipificação), a fim de que o propósito seja alcançado. Por exemplo, se o morador de uma comunidade quer expressar a sua opinião a respeito de um problema que afeta a população (propósito comunicativo), provavelmente ele vai recorrer a ações discursivas que o auxiliem. Para isso, ele deverá escolher dentre as diferentes possibilidades de realizações linguísticas que podem ajudá-lo em seu intento, como enviar uma carta de reivindicação à prefeitura, elaborar um abaixo-assinado ou enviar uma carta do leitor ao jornal da comunidade. Caso ele opte pela última opção, precisará conhecer as particularidades discursivas do gênero para que seu propósito seja completamente alcançado. Sob o prisma sociorretórico, é justamente a recorrência de situações que torna o gênero reconhecível.

Baseando-nos nessa visão de gênero como ação social, destacamos a importância de estudar os gêneros jornalísticos, porque tamanha é a influência exercida pela mídia na contemporaneidade, que alguns estudiosos a consideram o "Quarto Poder". Por se fazer tão presente na vida das pessoas, via publicações impressas, radiofônicas, televisivas ou eletrônicas, a mídia é um campo que vem cada vez mais sendo alvo de interesse de estudiosos da linguagem. Desse modo, faz-se importante estudar a mídia a partir de uma visão de gênero, pois não só possibilita que entendamos as ações discursivas realizadas por esse campo, como também serve de subsídios para atividades de leitura e produção textual, conforme sugerem os PCNs (BRASIL, 1998).

\subsection{O gênero reportagem}

No campo jornalístico, segundo Melo (1985), os gêneros jornalísticos podem ser divididos em duas grandes categorias: os que compõem o jornalismo opinativo e os que constituem o jornalismo informativo. Os gêneros do jornalismo opinativos têm a característica de que são produzidos com o propósito de expor a opinião do autor do texto. Os que compõem o jornalismo informativo visam a, em termos gerais, narrar fatos noticiosos.

A reportagem é um gênero considerado "problemático", pois se trata de uma atividade social que não possui definição clara dentro do campo linguístico, tampouco na literatura do jornalismo. Segundo Kindermann e Bonini (2006, p. 39), os estudos a respeito do gênero 
discursivo reportagem a caracterizam de dois modos básicos: como uma notícia ampliada e como um gênero autônomo.

Entre os autores que defendem a primeira visão, Kindermann (2003) destaca o posicionamento de Bahia (1990). Para ele, a reportagem é a grande notícia, defendendo que toda reportagem é uma notícia, porém nem toda notícia se constitui enquanto reportagem. A reportagem entendida como um gênero autônomo é defendido por Lage (1985). Para ele, “a reportagem não cuida da cobertura de um fato ou de uma série de fatos, mas do levantamento de um assunto conforme ângulo preestabelecido" (LAGE, 1985, p. 46).

No campo da Linguística, um dos autores que se dedicou a estudar a reportagem numa perspectiva de gêneros discursivos foi Charaudeau (2009). Para o autor, a "reportagem jornalística trata de um fenômeno social ou político, tentando explicá-lo" (CHARAUDEAU, 2009, p. 221), de modo que o fenômeno social é entendido pelo autor como uma série de acontecimentos produzidos no espaço público, gerando interesse geral.

Poderíamos citar outros pesquisadores de ambas as áreas que se dedicaram a estudar a reportagem, porém, esses três já nos permitem observar algumas características comuns da reportagem como gênero discursivo. Os três defendem que a reportagem apresenta como propósito comunicativo informar a respeito de um assunto (ou desdobramentos de um fato), não estando diretamente relacionados a temas do momento. Por isso, a reportagem é mais frequente em revistas e em edições específicas de jornais (como as publicações de finais de semana), pois para o jornalista construir uma reportagem é necessário tempo para investigação, levantamento de dados, entrevistas com testemunhas, especialistas, etc.

A reportagem, conforme Faria e Zanchetta Jr. (2007), apesar de procurar manter um caráter objetivo, apresenta um retrato do assunto a partir de um ângulo pessoal, com "contorno narrativo bem marcado" (FARIA; ZANCHETTA, 2007, p. 49), porque, ao contrário do que acontece na notícia, a reportagem é geralmente assinada pelo repórter, demonstrando que o que está sendo mostrado é feito a partir de um olhar específico.

Um recurso, apontado pelos autores, bastante frequente na construção das reportagens, que de certa forma refere-se ao aspecto objetivo buscado pelo texto jornalístico, é a inclusão de outras vozes no texto. Essa inclusão permite que o texto seja visto como abordando o tema de uma forma global e que o jornalista se isente da apresentação dos fatos. Por isso é recorrente em textos que instanciam o gênero reportagem a utilização de discurso direto e discurso indireto, com o intuito de marcar as outras vozes trazidas para o texto.

Após observarmos algumas características do gênero reportagem, apresentamos na seção seguinte informações a respeito da importância do contexto na análise de textos. 


\subsection{Texto e contexto}

É preciso ter em mente que qualquer realização textual de um gênero está situada em dado contexto. Como no caso do exemplo anteriormente citado, a carta do leitor produzida pelo morador da comunidade encontra-se inserida em um contexto (relaciona-se com a situação problemática, com a comunidade, com o veículo de publicação, etc.). Desse modo, partindo da noção de gênero como ação social, o contexto encontra-se diretamente implicado na produção textual. É justamente por esse fato que o entorno do texto deve ser considerado na análise.

Para que o invólucro textual seja devidamente estudado, este trabalho baseia-se na perspectiva contextual de Halliday (1989). Para o autor, “o contexto serve para fazer a ponte entre o texto e a situação na qual o texto geralmente ocorre", (HALLIDAY, 1989, p. 05), pois todo uso linguístico que possa ser considerado texto está sempre inserido em dois contextos: um de situação, mais imediato, e outro de cultura.

O contexto mais amplo, o de cultura, refere-se "ao ambiente social mais amplo, que inclui ideologia, convenções sociais e instituições" (FUZER; CABRAL, 2010, p. 16), ou seja, apresenta-se como um conjunto de experiências com significados compartilhados. O contexto de situação, por sua vez, caracteriza-se por ser o ambiente no qual o texto está efetivamente realizando uma função. Por isso, Halliday (1989) atribui a esse contexto significativa importância, pois a situação é capaz de dar aos participantes, durante uma interação linguística, uma grande ideia sobre os significados que estão sendo trocados e também aponta os que, provavelmente, serão ditos. A fim de analisar a situação em que o texto está funcionando, o teórico propõem três variáveis que definem o contexto situacional:

- Campo: dá conta da natureza da prática discursiva;

- Relações: estabelece o vínculo entre os participantes do discurso;

- Modo: corresponde ao papel que a linguagem desempenha na prática social.

As três variáveis, segundo a perspectiva de Halliday, são responsáveis por antecipar informações sobre o texto. Desse modo, configuram-se como essenciais em qualquer análise textual que entenda gênero como prática social.

Depois de apresentados os pressupostos teóricos que embasam esta pesquisa, descrevemos o percurso metodológico utilizado para a realização do objetivo proposto.

\footnotetext{
${ }^{2}$ Livre tradução para "So it [context] serves to make a bridge between the text and the situation in which texts actually occur".
} 


\section{Metodologia}

Para que o objetivo proposto fosse alcançado, foram selecionadas como corpus deste trabalho três reportagens da versão on-line da Revista IstoÉ. A seleção dos textos se deu por meio de dois critérios: a seção e o ano de publicação. As três reportagens ${ }^{3}$ são da seção "Comportamento" e foram publicadas nos últimos três anos (2009, 2010 e 2011). Encontramse disponíveis no site da revista, conforme links no Quadro 1.

\begin{tabular}{|c|c|c|c|c|}
\hline Código & Título & Autor & Seção & Publicação \\
\hline [R1] & $\begin{array}{l}\text { Crianças, as campeãs } \\
\text { de leitura }\end{array}$ & Rodrigo Cardoso & Comportamento & $\begin{array}{l}20 / 05 / 2009 \\
\text { ed. } n^{\circ} 2062\end{array}$ \\
\hline Link & \multicolumn{4}{|c|}{$\begin{array}{l}\text { http://www.istoe.com.br/reportagens/13388_CRIANCAS+AS+CAMPEAS+DE+LEI } \\
\text { TURA }\end{array}$} \\
\hline [R2] & Faça o que eu digo... & Verônica Mambrini & Comportamento & $\begin{array}{l}11 / 06 / 2010 \\
\text { ed. } n^{\circ} 2118\end{array}$ \\
\hline Link & \multicolumn{4}{|c|}{ http://www.istoe.com.br/reportagens/79760_FACA+O+QUE+EU+DIGO+ } \\
\hline [R3] & $\begin{array}{l}\text { Diga como chamas que } \\
\text { te direi quem és }\end{array}$ & Patrícia Diguê & Comportamento & $\begin{array}{l}20 / 01 / 2011 \\
\text { ed. } n^{\circ} 2151\end{array}$ \\
\hline Link & \multicolumn{4}{|c|}{$\begin{array}{l}\text { http://www.istoe.com.br/reportagens/121922_DIGA+COMO+CHAMAS+QUE+TE } \\
\text { +DIREI+QUEM+ES }\end{array}$} \\
\hline
\end{tabular}

Quadro 1 - Dados do corpus em estudo.

Selecionado o corpus do trabalho, a análise empreendida organiza-se em duas etapas: análise contextual e análise textual.

A etapa de análise do contexto visou a levantar informações sobre o veículo e sobre os textos em estudo. Compreendeu dois passos:

1. Coleta de informações a respeito da Revista IstoÉ;

2. Identificação das variáveis do contexto situacional campo, relações e modo das reportagens analisadas.

A análise textual compreendeu a identificação de aspectos linguísticos que caracterizam o gênero reportagem de revista:

\footnotetext{
${ }^{3}$ A fim de organizar a descrição da análise, utilizamos os seguintes códigos para nos referirmos aos textos que compõem o corpus: [R1] para Crianças, as campeãs de leitura; [R2] para Faça o eu digo...; e [R3] para Diga como chamas que te direi quem és.
} 
1. Identificação de quais são e como se realizam nos textos os fatores de textualidade;

2. Verificação das marcas linguísticas recorrentes nos textos;

3. Análise da relação existente entre o texto verbal e não-verbal.

Para que o objetivo seja devidamente alcançado, analisamos os textos em conjunto, a fim de podermos estabelecer relações com o gênero. Assim, descrito o caminho seguido na análise, apresentamos as características encontradas nos exemplares selecionados para o trabalho.

\section{Análise do corpus}

Nesta seção apresentamos dados contextuais e textuais que nos permitem caracterizar o gênero reportagem de revista, bem como identificar seu propósito comunicativo. Primeiramente, os dados obtidos com a análise contextual são apresentados (4.1) e, em seguida, os resultados da análise textual.

\subsection{Análise contextual}

Com o intuito de realizar o primeiro passo da etapa de análise contextual, apresentamos algumas informações acerca do veículo de divulgação dos textos analisados. Os três textos que compõem o corpus deste trabalho, como já foi mencionado, foram coletados do portal online da Revista IstoÉ (ou IstoÉ Independente). Revista semanal de circulação nacional, fundada no ano de 1976, é publicada pela Três Editoral Ltda. Voltada para o público adulto, a publicação possui tiragem de mais de 400 mil exemplares semanalmente. O periódico, segundo seu site, "pratica um jornalismo crítico, plural, democrático e compromissado apenas com o Leitor. Assim, investe todo seu esforço investigativo para levá-los a verdade dos fatos, através da informação precisa e independente".

A IstoÉ Independente apresenta, em sua versão online, seis macrosseções: Capa, Notícias, Colunas e Blogs, Multimídia, Serviços e Assuntos. Dessas macrosseções, interessa a este trabalho a última, pois dentre as seções que a formam, tais como A Semana, Brasil, Tecnologia \& Meio Ambiente, entre outras, encontra-se a seção Comportamento, da qual foram coletados os três textos analisados.

Depois de levantadas informações acerca do veículo de publicação, passemos à identificação das variáveis contextuais das reportagens. 
Com relação à variável campo, a qual objetiva identificar a prática discursiva que está sendo realizada (HALLIDAY, 1989), [R1] apresenta um estudo realizado pelo Observatório do Livro e da Leitura, o qual apresenta como resultado o aumento no índice de leitura entre a nova geração brasileira. O texto mostra também a influência dos pais e professores no crescimento dessa prática entre os leitores mirins.

Ainda observando essa variável, [R2] trata de uma pesquisa realizada pelo Instituto de Psicologia da Universidade de São Paulo sobre a maneira como os pais estão educando seus filhos atualmente. Os dados da pesquisa mostraram que a maioria dos pais se contradiz na hora de por em prática o que afirmam na teoria.

Considerando ainda a variável campo, a reportagem [R3] aborda a relação existente entre o nome com que os pais batizam os filhos e a sociedade. Segundo a matéria, a maneira como as famílias batizam a prole tem estreita relação com a posição e condição social dos pais.

Com base na identificação da variável campo, podemos destacar que, nos três casos, o objetivo do texto é apresentar informações, desdobramentos e exemplos a respeito de um assunto ligado a comportamentos e/ou hábitos humanos, reforçando a característica acima de que o gênero discursivo reportagem tem o propósito comunicativo de informar sobre um assunto (ou desdobramentos de um fato). Desse modo, podemos afirmar que objetivo das reportagens veiculadas na seção Comportamento da revista IstoÉ é trazer informações a respeito de hábitos e comportamentos humanos.

Tais informações são geralmente, dadas ao leitor por meio dos títulos e dos subtítulos das matérias, conforme os exemplos seguintes:

\section{CRIANÇAS, AS CAMPEÃS DE LEITURA}

Estudo revela que o público mirim é o que mais lê no País e mostra a importância da família na criação deste hábito [R1]

\section{FAÇA O QUE EU DIGO...}

... e não faça o que eu faço. Pesquisa revela como os pais caem em contradição na hora de educar seus filhos de 12 a 20 anos [R2]

\section{DIGA COMO CHAMAS QUE TE DIREI QUEM ÉS}

A forma como os pais batizam seus filhos diz muito sobre uma sociedade. No Brasil, famílias misturam tradição com modismo [R3]

Quanto à variável relações, cuja função é estabelecer o vínculo entre os participantes da interação e do texto, o primeiro aspecto possível de ser mencionado é o fato de os três textos serem assinados. Em [R1], o responsável pela matéria é o jornalista Rodrigo Cardoso; em 
[R2], a jornalista Verônica Mambrini; e, em [R3], a jornalista Patrícia Diguê, todos integrantes da equipe de reportagem da Revista, conforme consta no Expediente da Revista, cuja função é informar sobre a empresa que produz o periódico, os profissionais que nele atuam e suas funções, endereços, telefones e emails para que os leitores entrem em contato com a publicação. Na versão impressa da IstoÉ, o gênero discursivo expediente localiza-se, junto à seção destinada a publicação de cartas do leitor. Na versão online, há uma seção específica para o expediente (http://www.istoe.com.br/expediente/\#).

Esse aspecto encontrado no corpus em estudo reforça a premissa de que a reportagem tende, em um primeiro momento, a apresentar o assunto a partir de um dado ponto de vista, do jornalista que assina a matéria.

Quanto aos participantes do texto, observamos que não há interação entre eles, apenas são trazidos para exemplificar o assunto abordado ou outorgar o tema, por meio da posição social que ocupam, isto é, na qualidade de especialistas no assunto apresentado pela matéria. Desse modo, podemos observar os participantes textuais têm a função de garantir e comprovar o tema tratado nas reportagens.

Com relação à variável modo, podemos afirmar que os três textos foram publicados em versão impressa e online (www.istoe.com.br). Em [R1], o texto está organizado em nove parágrafos, duas fotografias e um infográfico. A reportagem [R2] é composta por cinco parágrafos, duas fotografias e um infográfico; e, em [R3], o texto é organizado por seis parágrafos, duas fotografias e um infográfico.

Ainda considerando essa variável, podemos constatar que, em relação ao modo de organização predominante, nas três reportagens predomina o modo expositivo, pois o objetivo dos textos é informar, apresentando ideias e opiniões de especialistas a respeito de um determinado tema.

\subsection{Análise textual}

Para a realização da etapa referente à análise textual, primeiramente identificamos os fatores de textualidade mais marcados. Observamos que o grau de informatividade do gênero reportagem de revista é alto, tendo em vista que o objetivo do gênero é apresentar informações, novas abordagens a respeito de um determinando assunto. Em [R1], o elevado nível de informatividade fica evidente logo no início do texto, conforme o seguinte excerto: 
Nas avaliações sobre língua portuguesa, os estudantes brasileiros costumam ter desempenho ruim em redação e compreensão de texto, uma das consequências dos baixos índices de leitura no País. Um levantamento inédito coordenado pelo Observatório do Livro e da Leitura (OLL) mostra que a nova geração pode ajudar a mudar este quadro. Segundo a pesquisa, as crianças são os que mais leem no Brasil: 6,9 livros por ano na faixa entre cinco e dez anos e 8,5 livros por ano entre 11 e 13 anos (leia quadro ao lado) [R1].

O fragmento mostra que a pesquisa apresentada na matéria aponta um dado novo no que se refere à questão de leitura no Brasil, indicando uma possível solução para o desempenho ruim dos estudantes.

Outro fator que identificamos como marcado é a situcionalidade. No gênero em estudo, o nível desse critério é baixo, pois a publicação dos textos não apresenta necessariamente correlação com uma dada situação do momento. Esse aspecto é evidente nos três textos analisados, não há relação entre as matérias e algum assunto (ou fato) debatido no momento de suas publicações, pois os temas abordados são, de certo modo, atemporais (hábito de leitura, educação dos filhos e nomes de batismo).

O terceiro critério que destacamos é a coesão, ou seja, os recursos linguísticos utilizados com o intuito de não só manter a unidade textual como também acrescentar e articular as informações novas. A manutenção da coesão nos textos é realizada por meio de processos remissivos, tais como pronomes, sinônimos, elipse, repetição, conforme o fragmento de [R3]:

Geralmente, os tradicionais têm raiz religiosa. E, se depender do papa Bento XVI, a presença deles só deve aumentar. Em 8 de janeiro, o pontífice recomendou aos cristãos optar por alcunhas religiosas ao batizar os rebentos. "Cada criança adquire o caráter de filho de Deus a partir de seu nome cristão", disse ele [R3] (Grifo meu).

O excerto exemplifica que, para se referir à palavra "nome", o produtor faz uso de elipses, "os [nomes] tradicionais têm raiz religiosa"; de pronomes, "a presença deles só deve aumentar"; de sinônimos, "optar por alcunhas religiosas"; e de repetição, "a partir de seu nome cristão".

A progressão das informações é realizada por meio de recursos sequenciais, como os encadeadores de relações lógico-semânticos indicadores de adversidade, conformidade, causalidade, etc. Tais operadores podem ser identificados no trecho a seguir:

A pedagoga Luciana chama a atenção para o fato de as contradições não estarem desligadas da vontade de acertar. Afinal, é difícil para os pais se 
desapegar da educação que receberam e, mais complicado ainda, encontrar uma nova forma de educar seus filhos. Mas vale a pena assumir as limitações para tornar a relação mais forte e sincera. Crianças e adolescentes, garantem os especialistas, têm uma facilidade de se adaptar, de melhorar e de se resolver enorme [R2].

No fragmento, foram destacados dois encadeadores do tipo lógico-semânticos: "mas", que estabelece uma relação de adversidade com a informação anterior, e "garantem os especialistas", indicando uma relação de conformidade com a informação posterior.

$\mathrm{Na}$ realização do segundo passo da análise textual, observamos que uma marca linguística predominantes é a utilização de inclusão de outras vozes nas reportagens. Recorrentemente os jornalistas fazem uso do depoimento de especialistas e de pessoas que vivenciam os temas abordados, para, conforme explicitado na análise da variável relações, exemplificar e confirmar a temática. Os exemplos que seguem deixam claro quem e qual o papel desempenhado pelas outras vozes trazidas para o texto:

A fonoaudióloga paulista Ana Clélia Rocha, 43 anos, costuma ler com a filha, Clara Santos, de oito anos, à noite e nos fins de semana. "É uma prática da família, não apenas por estudo, mas por prazer", explica Ana. [R1]

Essa questão faz parte da rotina de Liliane Neves Gomes, 41 anos, coordenadora de educação em uma escola em São Paulo e mãe de Lorenzo, 14 anos, Luísa, 13, e Bruno, 6. "Com meus pais, a gente sempre teve diálogo aberto, mas tinha rigidez e respeito", conta. "Aqui em casa negociamos mais." Liliane é adepta da conversa, mas faz uso do castigo quando ela falha. "Não fez lição de casa, respondeu mal ou virou o olho, vai ter uma sanção logo em seguida", afirma. [R2]

A influência pode ser mórbida. Mas, segundo estudiosos, tem explicação. "Até mesmo em casos como esses, as pessoas se influenciam pela mídia", analisa a sociolinguista Stella Maris Bortoni, professora da Faculdade de Educação da Universidade de Brasília (UnB). "Os nomes ficaram martelando por muito tempo. Além disso, eram moças bonitas e inocentes, que encantaram as pessoas". [R3]

No fragmento de [R1], a participante Ana Célia Rocha é apresentada como um exemplo de mãe que incentiva a filha a criar o hábito da leitura. Ainda com o intuito de exemplificar, o excerto de [R2] indica Liliane Neves Gomes como uma das mães que caem em contradição, pois mesmo sendo educadora profissional, conforme o texto destaca, na educação de seus filhos utiliza métodos considerados antiquados. Nesses dois trechos, as vozes trazidas para o texto têm o objetivo de exemplificar o assunto tratado em ambas as matérias. Já no trecho de [R3], o texto recorre ao depoimento de especialistas. Nele, para justificar a escolha de nomes 
de pessoas envolvidas em tragédias (como Elisa e Isabela) pelos pais na hora de batizar os filhos, o jornalista apresenta o posicionamento da sociolinguista Stella Maris Bortoni sobre o fato.

Dessa maneira, a utilização de discurso direto e indireto serve para, conforme Faria e Zanchetta Jr. (2007), tentar manter o caráter objetivo do texto, indicando que as informações apresentadas não são apenas afirmações do jornalista, mas dados confirmados por especialistas e exemplificados por pessoas diretamente ligadas aos comportamentos e hábitos apresentados nas matérias.

Finalizando a etapa de análise textual, observamos que a relação entre os elementos verbais e não verbais. Entre o verbal e as fotografias, observamos que a relação é de ilustração. As imagens utilizadas não acrescentam nenhum dado novo ao verbal, por exemplo, em [R3], a reportagem apresenta uma foto da atriz Fernanda Lima com seus filhos (Figura 1).

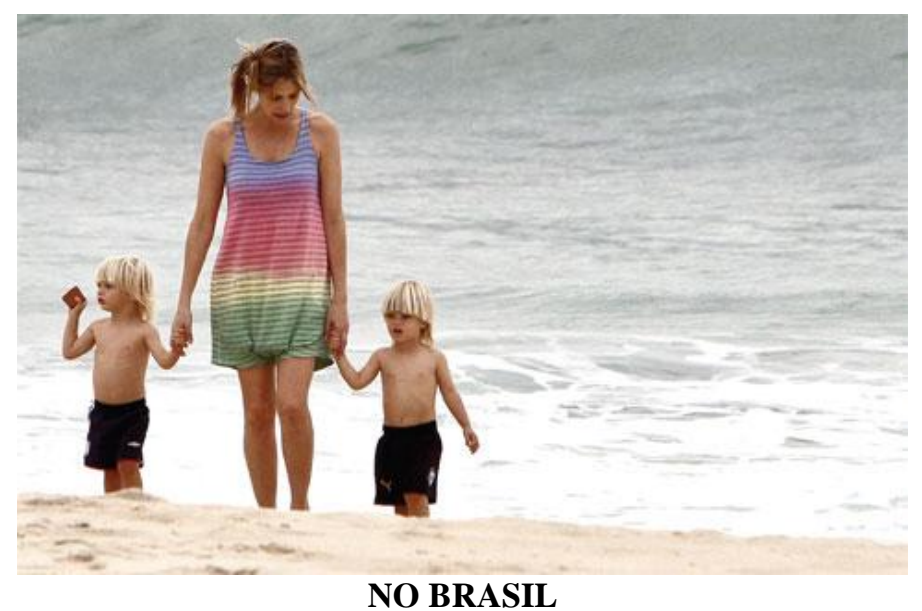

A classe média adotou os tradicionais, como a atriz Fernanda Lima que deu a seus gêmeos os nomes de João e Francisco

Figura 1 - Foto e legenda em R3.

O elemento verbal apresenta o seguinte excerto:

Outra tendência que se observa no Brasil é a recente popularidade de nomes tradicionais nas classes mais privilegiadas. As celebridades são o termômetro. Entre elas, os atores Fernanda Lima e Rodrigo Hilbert batizaram seus gêmeos de 2 anos de João e Francisco. Até a última década, no entanto, esses nomes eram típicos de classes menos favorecidas, garantem os estudiosos [R3] (Grifo meu).

Podemos, portanto, notar que a relação entre elemento verbal e fotográfico é de ilustratividade. A fotografia tem o objetivo de apenas mostrar as celebridades mencionadas no 
texto [R3], os pais e os filhos [R2] e o local onde as crianças praticam a leitura [R1], e, por isso, despertar o interesse do leitor na matéria.

Por outro lado, os infográficos apresentam relação de complementaridade com o texto verbal, apresentando informações novas. Em [R2], por exemplo, é apresentado um infográfico (Figura 2) que apresenta alguns resultados numéricos encontrados pela pesquisa realizada com os pais sobre a educação dos filhos.

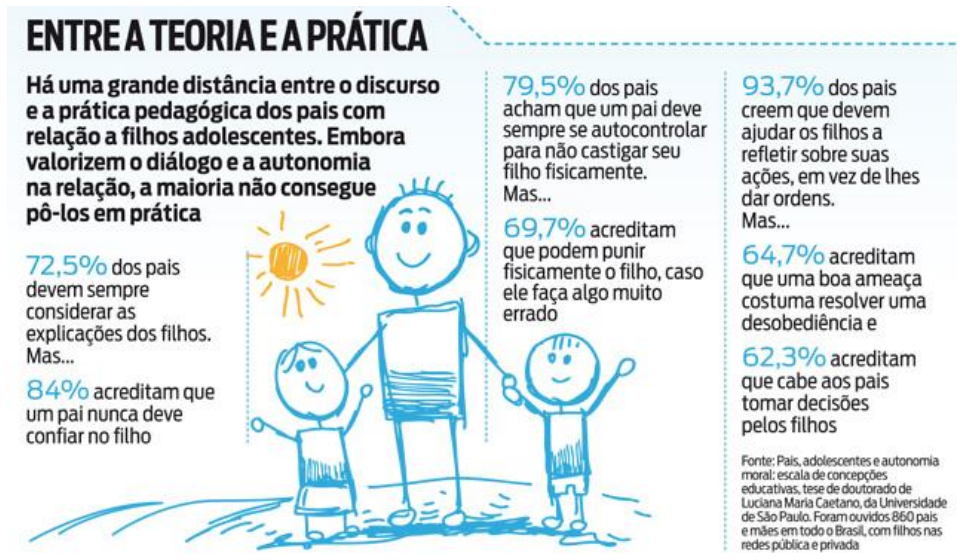

Figura 2 - Infográfico em R2.

Por sua vez, o elemento verbal refere-se ao infográfico da seguinte forma:

O levantamento, liderado pela pedagoga Luciana Maria Caetano, que também é professora da Universidade São Francisco (USF), comprovou que o dito popular "faça o que eu digo e não o que eu faço" é utilizado, involuntariamente, pela maioria dos pais. De acordo com a pesquisa, 93,7\% deles creem que devam ajudar os filhos a refletir sobre suas ações, em vez de lhes dar ordens. Mas 64,7\% também acreditam que uma boa ameaça acaba com uma desobediência (Ler outros exemplos no quadro) [R2] (Grifo meu).

Desse modo, podemos afirmar que, nas reportagens analisadas, as fotografias cumprem um papel ilustrativo, com a função de atrair a atenção do leitor para o texto. Os infográficos, por sua vez, têm a função de complementar as informações trazidas no corpo do texto.

\section{Considerações finais}

Este trabalho teve por objetivo verificar como o gênero reportagem de revista se configura em relação à ação social realizada, aos aspectos contextuais e às características linguísticas, visando a apontar alguns aspectos que podem colaborar com o trabalho de 
gêneros jornalísticos em sala de aula. Para isso, selecionamos como corpus três reportagens da seção "Comportamento", da Revista IstoÉ, publicadas nos três últimos anos (2009, 2010 e 2011). Teoricamente, baseamo-nos na perspectiva sociorretórica, que entende gênero como ação social, nos estudos de Halliday (1989) sobre contexto de situação, na Linguística Textual para análise da linguagem verbal e nos estudos de multimodalidade para identificarmos a relação entre elemento não verbal e verbal.

Com relação à prática social realizada, concluímos que o propósito comunicativo da reportagem é informar a respeito de um assunto, o qual pode ou não estar relacionado com algum fato discutido no momento. Especificamente, na seção em análise, os textos que realizam o gênero versam sobre comportamentos e hábitos humanos.

Sobre os aspectos interacionais, verificamos que as reportagens do periódico apresentam sempre um repórter responsável por assinar a matéria. Além disso, os participantes do texto são trazidos a fim de assegurar e demonstrar a temática abordada, não apresentando interação direta entre si.

Quanto à organização do gênero reportagem, na seção analisada, o texto é composto por elemento verbal, fotografias e infográficos. As reportagens apresentam predominantemente o modo expositivo, reforçando o propósito comunicativo do gênero, informar a respeito de um assunto.

Um dos aspectos linguísticos levantados foi o uso de inclusão de vozes, com o objetivo de manter a suposta objetividade jornalística tão desejada. $\mathrm{O}$ outro corresponde à relação entre os elementos verbais e não verbais, de modo que constatamos a relação de ilustratividade entre verbal e fotografias e de complementaridade entre o texto verbal e o infográfico. A ilustratividade das fotografias tem o objetivo de despertar o interesse do leitor, pois, ao folhear as páginas da revista e se deparar com a imagem de uma celebridade, por exemplo, o leitor tende a parar e ler a matéria. A complementaridade dos infográficos, por sua vez, tem a função de enxugar o conteúdo do texto, pois apresenta em forma de tabulação informações que o jornalista considera como de segundo plano. O estudo dessa relação indica que os elementos não verbais deixam de ser encarados como decoração para o verbal e passam a um papel na leitura do texto como um todo.

Para concluir, retomamos a importância de trabalhar, em aula de língua, a noção de gênero discursivo, pois a partir do levantamento de seus aspectos contextuais e linguísticos podemos observar de que modo cada gênero cumpre uma função social, possibilitando que as pessoas se engajem em práticas discursivas. Desse modo, o estudo em sala de aula deixa de 
ser uma prática deslocada da vida social e passa a trafegar em sentido contrário, trazendo as práticas sociais para o ensino de língua materna.

Como estudos futuros, indicamos a análise de um número maior de textos e oriundos de outras seções da mesma revista, para que, de modo contrastivo, possa-se verificar se as características identificadas estendem-se aos demais exemplares de reportagens que compõem a publicação.

\section{Referências bibliográficas:}

BAKHTIN, M. Os gêneros do discurso. In: . Estética da criação verbal. São Paulo: Martins Fontes, 1992, p. 277-326.

BAZERMAN, C.; DIONÍSIO, A. P.; HOFFNAGEL, J. C. (Orgs.). Gêneros textuais, tipificação e interação. São Paulo: Cortez, 2005.

BRASIL. Parâmetros Curriculares Nacionais. Secretaria de Educação Fundamental. Língua Portuguesa. Brasília: MEC/SEF, 1998.

BRONCKART, J. P. Atividade de linguagem, textos e discursos: por um interacionismo sociodiscursivo. São Paulo: EDUC, 1990.

CARDOSO, R. Crianças, as campeãs de leitura. IstoÉ, São Paulo, 20 mai. 2009. http://www.istoe.com.br/reportagens/13388_CRIANCAS+AS+CAMPEAS+DE+LEITURA. Acesso em 09 mai. 2011.

CHARAUDEAU, P. Discurso das mídias. São Paulo: Contexto, 2009.

FARIA, M. A.; ZANCHETTA JR., J. Para ler e fazer o jornal na sala de aula. São Paulo: Contexto, 2007.

FUZER, C; CABRAL, S. R. S. Introdução à gramática sistêmico-funcional em língua portuguesa. Santa Maria, RS: UFSM/CAL/DLV, 2010.

JORDÃO, C. Diga como chamas que te direi quem és. IstoÉ, São Paulo, 02 fev. 2011. Disponível em: <http://www.istoe.com.br/reportagens/121922_DIGA+COMO+CHAMAS+ QUE+TE+DIREI+QUEM+ES>. Acesso em 09 mai. 2011.

HALLIDAY, M. A. K.; HASAN, R. Language, context, and text: aspects of language in a social-semiotic perspective. 2. ed. Oxford: Oxford University Press, 1989.

KINDERMANN, C. A. A reportagem jornalística no Jornal do Brasil: desvendado as variantes do gênero. 2003. 141f. Dissertação (Mestrado em Ciências da linguagem) Universidade do Sul de Santa Catarina, Tubarão, SC, 2003.

KINDERMANN, C. A.; BONINI, A. A reportagem jornalística: uma caracterização inicial do gênero a partir de exemplares publicados no Jornal do Brasil. In: MOTTA-ROTH, D.; 
BARROS, N. C. A.; RICHTER, M. G. (Orgs.). Linguagem, cultura e sociedade. Santa Maria: UFSM, 2006, p. 39-56.

LAGE, N. Estrutura da notícia. São Paulo: Ática, 1985.

MAMBRINI, V. Faça o que eu digo... IstoÉ, São Paulo, 11 jun. 2010. Disponível em: <http://www.istoe.com.br/reportagens/79760_FACA+O+QUE+EU+DIGO+>. Acesso em: 30 mai. 2011.

MARCUSCHI, L. A. Gêneros textuais: definição e funcionalidade. In: DIONÍSIO, A. P.; MACHADO, A. R.; BEZERRA, M. A. (Org.). Gêneros textuais \& ensino. Rio de Janeiro: Lucerna, 2002, pp. 19-36.

MELO, J. M. A opinião no jornalismo brasileiro. Petrópolis, RJ: Vozes, 1994.

MILLER, C. Genre as Social Action. In: FREEDMAN, A.; MEDWAY, P. (Orgs.). Genre and New Rethoric. London: Taylor \& Francis, 1994, p. 23-42.

Gênero como ação social. In: Estudos sobre gênero textual, agência e tecnologia. Recife: Ed. Universitária da UFPE, 2009, p. 21-44.

SWALES, J. M. Genre analysis: English in academic and research settings. Cambridge: Cambridge University Press, 1990.

The weekly paper report as a discoursive genre: a study of its characteristics and the analysis of some titles of Istoé

\begin{abstract}
This work aims at identifying the configuration of news report as a genre, previous studies, and at verifying how these characteristics are instantiated in some samples published in a wide-circulation Brazilian magazine. Therefore, it points out some aspects that can be considered in the teaching of Portuguese, once the main documents, such as the PCN-LP, suggest that teachers use the different genres as the starting point of the teaching process.
\end{abstract}

Key words: Genre. News report. Context. Text. 